\title{
Effect on lipopolysaccharide structure of aeration during growth of a plum isolate of Pseudomonas syringae pv. morsprunorum
}

\author{
A. R. W. Smith, ${ }^{1}$ S. M. Munro, ${ }^{1}$ R. Wait ${ }^{2}$ and R. C. Hignett ${ }^{1} \dagger$ \\ Author for correspondence: A. R. W. Smith. Tel: +4481316 8221. Fax: +44813168305.
}

1 School of Biological and Chemical Sciences,

University of Greenwich, Wellington Street, London SE18 6PF, UK

2 Public Health Laboratory Service, Centre for Applied Microbiology Research, Porton Down, Salisbury SP4 0JG, UK
The composition of lipopolysaccharide (LPS) extracted with aqueous phenol from a virulent English plum isolate of Pseudomonas syringae pv. morsprunorum varied according to the partial pressure of oxygen $\left(\mathrm{pO}_{2}\right)$ in the culture medium at the time of harvest. When $\mathrm{pO}_{2}$ was low, the organism grew slowly and produced smooth LPS bearing rhamnan sidechains. $\mathrm{As}^{\mathrm{PO}_{2}}$ was raised, the rate of growth increased and smooth LPS was replaced by a rough species deficient in rhamnose, which co-extracted with a D-glucan.

Organization of rhamnose and glucose into separate polymers was shown by the selective susceptibility of the rhamnose-containing polymer to hydrolysis by rhamnanase of the phage A7. By methylation analysis, GC-MS, and ${ }^{1} \mathrm{H}$ - and ${ }^{13} \mathrm{C}$-NMR spectroscopy, the glucan was shown to consist of $\alpha(1 \rightarrow 4)$-linked residues with $\alpha(1 \rightarrow 4,6)$-branch points and non-reducing terminal residues in the approximate ratio 4:1:1, resembling glycogen in composition. A glucan which co-extracted with LPS using phenol/water from an avirulent plum isolate that was resistant to lysis by phages A1 and A7 was shown by methylation analysis to have a similar structure. Whether the effect on LPS composition was due directly to $\mathrm{pO}_{2}$, or was dependent on the rate of growth, has not been established. It is suggested that, because epiphytic growth would entail exposure to high $\mathrm{pO}_{2}$, English plum isolates growing on the surfaces of host plants might be unable to produce smooth LPS. Since cell surface composition affects virulence in plant-pathogenic pseudomonads, this effect could account for the observed failure of the English plum isolates to enter the host via leaf scars.

Keywords: Pseudomonas syringae pv. morsprunorum, lipopolysaccharide, glycogen, aeration

\section{INTRODUCTION}

Pseudomonas syringae pv. morsprunorum causes bacterial canker in cherry and plum. The side-chain of lipopolysaccharide (LPS) from the English cherry isolate C28 is composed of a rhamnan linked in the repeat sequence

3)- $\alpha$-D-Rha $p(1 \rightarrow 3)-\alpha-\mathrm{D}-\mathrm{Rha} p(1 \rightarrow 2)-\alpha$-D-Rhap-(1 $\rightarrow$

(Smith et al., 1985b). Glycosidic bonds at 2)- $\alpha$-D-Rhap(1 $\rightarrow 3$ are hydrolysed by the phage A7, which uses LPS as

\footnotetext{
†Present address: Department of Science, Mid-Kent College of Higher and Further Education, Horstead, Maidstone Road, Chatham ME5 9UQ, UK.

Abbreviations: KDO, 3-deoxy-2-octulosonic acid; PMAA, partially-methylated alditol acetate; TMS, tetramethylsilane.
}

its binding site, releasing tri- and hexasaccharides in equimolar proportion (Smith et al., 1994).

Garrett et al. (1974) showed that phage-resistant mutants of cherry isolates of the pv. morsprunorum displayed diminished virulence. Mutants resistant to phages binding LPS, such as A7, have altered LPS structure. Zamze $e t$ al. (1985) found that three phage A7-resistant mutants of strain C28 contained rough LPS. A fourth mutant, D17A1R, derived from the cherry-type plum isolate D17 by selection for resistance to the related phage A1, apparently bore side-chains composed entirely of glucose.

Zamze et al. (1985) found that the side-chains of LPS from the plum isolate D10, which was cultured in stirred 11 conical flasks, appeared to be composed of rhamnose with a small amount of glucose. It was later found that when the organism was cultured in a baffled aerated fermenter, 
the LPS recovered apparently bore side-chains composed of a glucan. In this paper, we describe this effect and compare the structures of the glucans from strains D10 and D17-A1R. A preliminary report of this work was given by Munro et al. (1986).

\section{METHODS}

Organisms. D10, a typical virulent English plum isolate of $P$. syringae pv. morsprunorum, was originally supplied by $\mathrm{Dr}$ C. M. E. Garrett, Horticultural Research International, East Malling, Kent, UK. D17-A1R, a mutant of diminished virulence, was selected by Garrett et al. (1974) for resistance to phage A1 from strain D17, an atypical virulent English plum isolate sensitive to phages A1 and A7 (Crosse \& Garrett, 1963). D17A1R was also resistant to phage A7. Both bacterial strains, and bacteriophage A7 (Smith et al., 1994), were propagated, assayed and stored as described by Smith et al. (1985a).

Bulk culture of bacteria and extraction of LPS. Bacteria were cultured at $18^{\circ} \mathrm{C}$ in glucose-minimal salts medium (Smith et al., 1985a). Dissolved oxygen tension was measured using a steamsterilizable galvanic lead electrode (Borkowski \& Johnson, 1967).

Strain D10 was grown in stirred, baffled 11 Erlenmeyer flasks containing $250 \mathrm{ml}$ portions of medium, and harvested at late exponential phase $\left(\mathrm{OD}_{540}=2 \cdot 0\right)$, as described by Smith et al. (1985a). The organism was also grown in 81 batches by drawand-fill technique, in a type 1/1000 LHE fermenter (LH Engineering) fitted with a $10 \mathrm{l}$ stirred, baffled vessel, with agitation and aeration rates of 750 r.p.m. and 21 air $\mathrm{min}^{-1}$ respectively (described below as moderate aeration). Growth under conditions of vigorous aeration was provided by raising the agitation and aeration rates to 1250 r.p.m. and $5 \mathrm{l}$ air $\mathrm{min}^{-1}$, respectively. Strain D17-A1R was routinely grown with moderate aeration.

Fermenter cultures were checked daily for purity by testing for characteristic colony morphology and levan production (Garrett et al., 1966), and for induction of the hypersensitive response in tobacco (Klement, 1963).

LPSs were extracted from cells using aqueous phenol and purified as described previously (Smith et al., 1985a, b).

Partial hydrolysis of LPS by phage A7. High- and low $-M_{r}$ products generated by the action of phage A7 on LPS from cells of strain D10 grown with poor or moderate aeration were separated by ultracentrifugation. Oligosaccharides in the low$M_{\mathrm{r}}$ fraction were then resolved chromatographically using Sephadex G-25 (Smith et al., 1994).

Analytical and chromatographic methods. Most procedures employed for the analysis of LPS, the hydrolysis with $1 \%(\mathrm{v} / \mathrm{v})$ acetic acid and de-O-acylation of LPS in alkali, and gel permeation chromatography of the products, were those of Smith et al. (1985a, b). Total carbohydrate, KDO and glucose were determined in the free polysaccharide moiety or in whole LPS after acid hydrolysis. Samples were treated with $0.5 \mathrm{M} \mathrm{H}_{2} \mathrm{SO}_{4}$ for $3.5 \mathrm{~h}$ at $105{ }^{\circ} \mathrm{C}$ under $\mathrm{N}_{2}$ in sealed glass ampoules, neutralized with Dowex- 1 resin $\left(\mathrm{OH}^{-}\right.$form), and clarified by passage through a sintered glass filter. Total carbohydrate was determined by the phenol/sulphuric acid reaction (Dubois et al., 1956) using L-rhamnose or D-glucose as the standard. Rhamnose was determined separately using the cysteine/sulphuric acid method (Osborn, 1963); D-glucose was estimated enzymically with glucose oxidase (kit no. 510; Sigma) after hydrolysis with $2 \mathrm{M} \mathrm{HCl}$.

Neutral sugars released by hydrolysis of side-chain poly. saccharides were identified by descending paper chromatography (Smith et al., 1985a), and were determined by gas chromatography (GC) as their alditol acetates (Zamze et al., 1986), using a $1.83 \times 0.64 \mathrm{~cm}$ column of GP $3 \%$ SP-2340 on Supelcoport $100 / 120$ (Supelco) with temperature programming from 170 to $270^{\circ} \mathrm{C}$ at $2{ }^{\circ} \mathrm{C} \mathrm{min}-1$. Response factors for flame ionization detection were calculated using derivatized mixtures of standard sugars in equimolar proportion.

Polyacrylamide gel electrophoresis of LPSs. Intact LPSs were submitted to PAGE and silver-stained by the procedure of Aucken \& Pitt (1993).

Absolute configuration of rhamnose and glucose. The absolute configuration of rhamnose was determined by GC of the acetylated oct-2-yl rhamnosides (Smith et al., 1985b). The configuration of glucose was determined by submitting hydrolysed samples of the glucan from LPS of strain D10 to estimation by D-glucose oxidase, and comparing the values with those from determinations made with phenol/sulphuric acid.

Methylation analysis of oligo- and polysaccharides. Polysaccharides $(6-10 \mathrm{mg})$, or oligosaccharide derived by digestion with phage A7 (3-6 mg), were methylated in dimethyl sulphoxide (DMSO) and recovered and analysed as described by Smith et al. (1985b, 1994). GC-mass spectrometry was performed as described by Ray et al. (1987), except that chromatography on SE30 was performed with temperature programming from 120 to $200^{\circ} \mathrm{C}$ at $10^{\circ} \mathrm{C} \mathrm{min}^{-1}$.

NMR spectroscopy. NMR spectra of oligo- and polysaccharides were recorded in $100 \% \mathrm{D}_{2} \mathrm{O}(2.5 \mathrm{ml})$ in a Bruker WH-400 spectrometer (Smith et al., 1994). ${ }^{1} \mathrm{H}-\mathrm{NMR}$ spectra of the polysaccharides $(20 \mathrm{mg}$ ) liberated by mild acid hydrolysis from LPSs of cells of strain D10 grown with moderate and vigorous aeration were recorded at $400.13 \mathrm{MHz}$, at $358 \mathrm{~K}$, relative to internal DOH ( $\delta=4.30$ p.p.m.), with a pulse width of $4 \mu \mathrm{s}$, and acquisition times of $3.998 \mathrm{~s}$ and $1.524 \mathrm{~s}$ for the two respective polysaccharides.

The ${ }^{13} \mathrm{C}$-NMR spectrum of the polysaccharide $(20 \mathrm{mg})$ from strain D10 cells grown with vigorous aeration was recorded at $100.62 \mathrm{MHz}$, at $358 \mathrm{~K}$ with complete proton decoupling, relative to TMS ( $\delta=-2 \cdot 167$ p.p.m.) in a capillary tube, and 36503 accumulations of free induction decay were made, with a pulse width of $10 \mu$ s and an acquisition time of $0.655 \mathrm{~s}$. A completely coupled ${ }^{13} \mathrm{C}-\mathrm{NMR}$ spectrum was also obtained from 33596 accumulations of free induction decay, with a pulse width of $10 \mu \mathrm{s}$, an acquisition time of $0.655 \mathrm{~s}$ and an interpulse spacing of $1 \cdot 655 \mathrm{~s}$.

\section{RESULTS}

\section{Extraction and purity of LPS from strains D10 and D17-A1R}

Yields of acetone-dried cells from strains D10 and D17A1R grown in 81 batches in the fermenter were typically $1 \cdot 1-1 \cdot 3 \mathrm{~g}(1 \mathrm{medium})^{-1}$. Dried cells of strains D10 and D17-A1R yielded $2 \cdot 5-3 \cdot 0 \%$ and $1 \cdot 0 \%(\mathrm{w} / \mathrm{w})$ respectively of LPS, which contained approximately $1.5 \%(\mathrm{w} / \mathrm{w})$ nucleic acid and $1-2 \%(\mathrm{w} / \mathrm{w})$ protein.

\section{Culture $\mathrm{pO}_{2}$ and sugar content of whole LPS from strain D10}

As found previously by Zamze et al. (1985), strain D10 yielded LPS containing side-chains composed almost exclusively of rhamnose (type A LPS) when grown in stirred, baffled 11 flasks. During the present investigation, this polymer was shown by methylation analysis, ${ }^{1} \mathrm{H}$ - and 


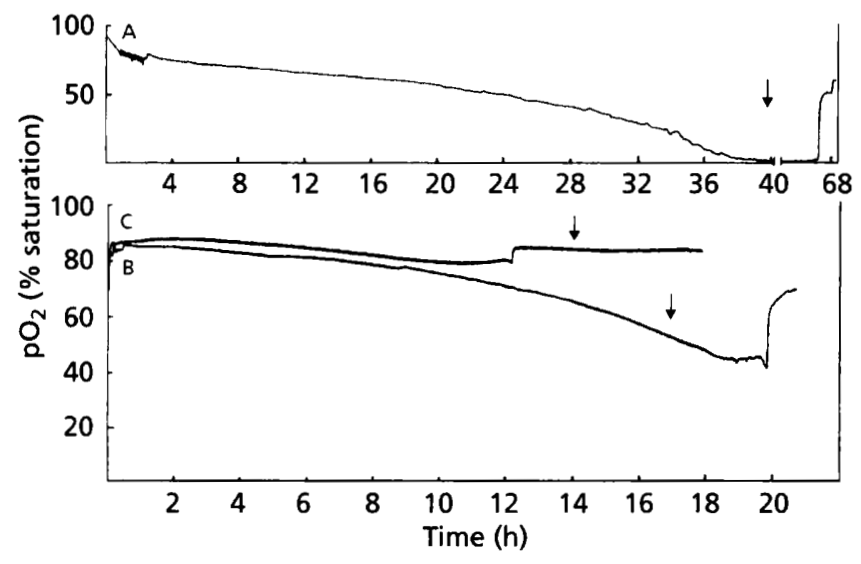

Fig. 1. Changes in $\mathrm{pO}_{2}$ of culture medium of strain $\mathrm{D} 10$ grown under different conditions. Partial pressures of oxygen were measured using a galvanic lead electrode. A, cultures grown in stirred, baffled Erlenmeyer flasks yielding low $\mathrm{pO}_{2}$ conditions; $B, C$, cultures grown in a baffled fermenter stirred at 750 r.p.m. and aerated at $2 \mathrm{I}$ air $\mathrm{min}^{-1}$, and 1250 r.p.m. and $5 \mathrm{I}$ air $\mathrm{min}^{-1}$ (medium and high $\mathrm{pO}_{2}$ conditions respectively). Vertical arrows indicate routine times of harvest.

${ }^{13} \mathrm{C}$-NMR spectroscopy to be structurally identical with the rhamnan from the cherry isolate $\mathrm{C} 28$ described by Smith et al. (1985a, b).

When cultured in the fermenter with vigorous aeration, strain D10 yielded a second form of LPS (type B) in which glucose had apparently replaced rhamnose. With moderate aeration, the organism produced an intermediate form (type AB LPS) containing both sugars.

The organisms recovered from fermenter cultures were invariably indistinguishable from strain $\mathrm{D} 10$ on the basis of their colony morphology, ability to produce levan on nutrient sucrose agar, induction of the hypersensitive response in tobacco, and sensitivity to phage A7. Production of the novel LPS was therefore not due to the emergence of a contaminant during bulk culture. Nor could the altered composition be ascribed to differences in growth medium, temperature or $\mathrm{pH}$, since the same medium and temperature were used throughout, and the same $\mathrm{pH}(6.4)$ was reached at the time of harvest. However, the terminal $\mathrm{pO}_{2}$ in the various cultures differed considerably. Production of type A LPS correlated with low terminal $\mathrm{pO}_{2}$; types $\mathrm{AB}$ and $\mathrm{B}$ LPSs were produced at progressively higher $\mathrm{pO}_{2}$ values.

Fig. 1 shows the changes in culture $\mathrm{pO}_{2}$ during growth of strain D10 in stirred, baffled flasks, and in moderately- and vigorously-aerated fermenter cultures. The approximate times of harvesting for routine extraction of LPS are indicated in each case. In flask culture, $\mathrm{pO}_{2}$ during growth fell at a uniform rate to $0 \%$ saturation, and returned sharply to the original level when growth ceased. In fermenter cultures given moderate aeration, $\mathrm{pO}_{2}$ fell to $45 \%$ saturation before returning to the initial value when growth ceased. With vigorous aeration, the minimal value in culture was $77 \%$. Since the medium was carbonlimited, the cessation of $\mathrm{O}_{2}$ consumption apparently corresponded in each case with glucose depletion. Typical times taken to reach the break-point were $67 \mathrm{~h}$ for growth in flasks, and $20 \mathrm{~h}$ and $12 \mathrm{~h}$ in moderately-and vigorouslyaerated fermenter cultures, respectively, indicating (not unexpectedly) that the growth rate was lower when oxygen became a limiting factor.

Cultures were routinely harvested for extracting LPS when the $\mathrm{OD}_{540}$ reached $2 \cdot 0$. At this point, typical values for $\mathrm{pO}_{2}$ were $25 \%, 53 \%$ and $84 \%$ saturation for flask cultures, and moderately- and vigorously-aerated fermenter cultures respectively.

Table 1 shows the content of rhamnose and glucose in LPSs extracted from cells grown under each set of

\section{Table 1. Rhamnose and glucose content of intact LPS from strain D10 grown at differing $\mathrm{pO}_{2}$ values}

Organisms were cultured as described in Methods, using a galvanic electrode to determine dissolved $\mathrm{pO}_{2}$ values. Glucose and rhamnose were estimated using glucose oxidase and cysteine $/ \mathrm{H}_{2} \mathrm{SO}_{4}$ respectively.

\begin{tabular}{|c|c|c|c|c|c|c|c|}
\hline \multirow[t]{2}{*}{ Culture conditions } & \multirow{2}{*}{$\begin{array}{c}\mathrm{pO}_{2} \text { of } \\
\text { culture at } \\
\text { harvest } \\
(\% \\
\text { saturation) }\end{array}$} & \multicolumn{4}{|c|}{ Carbohydrate $\left[\mu \mathrm{mol}(\mathrm{mg} \mathrm{LPS})^{-1}\right]$} & \multirow{2}{*}{$\begin{array}{l}\text { Glc: } R \text { ha } \\
\text { ratio in } \\
\text { poly- } \\
\text { saccharide } \\
\text { fraction }\end{array}$} & \multirow{2}{*}{$\begin{array}{l}\text { Type of } \\
\text { LPS }\end{array}$} \\
\hline & & Glucose & Rhamnose & Total* & Glc: Rha & & \\
\hline \multirow[t]{2}{*}{ Stirred baffled flask } & 25 & $0 \cdot 18$ & $1 \cdot 36$ & $1 \cdot 54$ & $0 \cdot 13$ & $0 \cdot 16$ & $A$ \\
\hline & ND & $0 \cdot 29$ & 1.33 & $1 \cdot 62$ & $0 \cdot 22$ & ND & ND \\
\hline \multicolumn{8}{|c|}{ Stirred aerated baffled fermenter } \\
\hline \multirow[t]{2}{*}{750 r.p.m.; 21 air $\mathrm{min}^{-1}$} & 53 & $0 \cdot 24$ & $0 \cdot 55$ & 0.79 & $0 \cdot 44$ & 0.63 & $\mathrm{AB}$ \\
\hline & ND & $0 \cdot 37$ & $0 \cdot 64$ & $1 \cdot 01$ & 0.58 & ND & ND \\
\hline \multirow[t]{2}{*}{1250 r.p.m.; 51 air $\min ^{-1}$} & 84 & $1 \cdot 02$ & $0 \cdot 38$ & $1 \cdot 40$ & $2 \cdot 68$ & $33 \cdot 6$ & B \\
\hline & ND & $1 \cdot 41$ & $0 \cdot 31$ & $1 \cdot 72$ & $4 \cdot 55$ & ND & ND \\
\hline
\end{tabular}

ND, Not determined.

* Total glucose + rhamnose. 


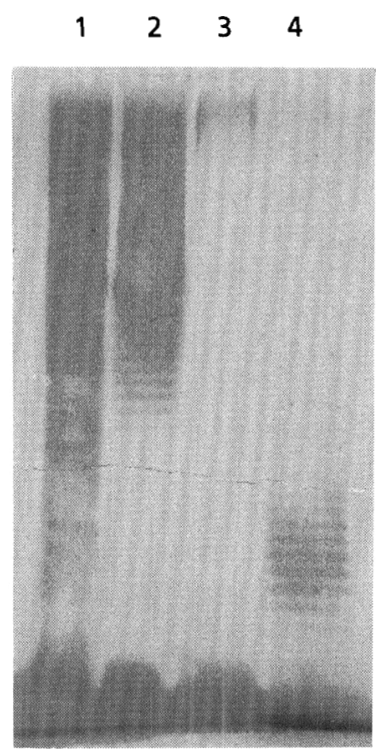

Fig. 2. SDS-PAGE of LPSs from strains of $P$. syringae pv. morsprunorum. LPS samples ( $30 \mu \mathrm{l}$, denatured by heat treatment with SDS) were loaded onto a $10 \%$ separating polyacrylamide gel slab $(13 \times 18 \mathrm{~cm})$ surmounted by $5 \%$ stacking gel, submitted to electrophoresis in a discontinuous Tris/glycine buffer containing SDS, then fixed and stained with silver as described in Methods. Lanes contain LPS of: 1, strain C28 (a cherry isolate: see Smith et al., 1985a); 2, cells of strain D10 harvested at low $\mathrm{pO}_{2} ; 3$, cells of strain D10 harvested at high $\mathrm{pO}_{2} ; 4$, strain D17-A1R. Origins are situated at the top of the photograph.

conditions, in relation to the $\mathrm{pO}_{2}$ at the point of harvest. Glucose: rhamnose ratios increased with increasing dissolved $\mathrm{pO}_{2}$, but for ratios of $0.13,0.44$ and 2.68 the combined quantities of the two sugars per mg of LPS were $1.54,0.79$ and $1.40 \mu \mathrm{mol}$ respectively. The rhamnose content therefore fell before the glucose content was appreciably increased.

\section{Structure of type B LPS from strain D10}

To determine whether glucose was attached to the lipid A in type B LPS, samples $(20 \mathrm{mg})$ were de-O-acylated with ethanolic alkali and fractionated on Sephadex G-200. The carbohydrate content of the deacylated LPS was com. pletely recovered in a single peak that co-eluted with the single peak of KDO. The molar ratio of KDO: glucose in the combined peak fractions was 1:27, which corresponded closely with that for native LPS $(1: 23)$. Coelution indicated that the glucose content was covalently joined with the KDO; but this interpretation was not supported by an examination of silver-stained SDS. polyacrylamide electrophoretograms of intact LPSs (Fig. 2 ). The banding pattern of smooth LPS typically appears on gels as a ladder-like profile, due to the presence of multiple molecular species of differing side-chain length (Helander, 1985); rough LPSs give only a fast-moving band formed by lipid A units bearing only core oligo- saccharide. In the present comparison, only LPS from cells grown with poor aeration yielded the ladder pattern. LPS from cells grown with vigorous aeration gave only the fast-moving band formed by rough LPS. With the latter sample, a small amount of silver-stained material, possibly uncharged polysaccharide, was detected at the site of application to the gel.

\section{Composition of LPSs from strain D10}

Analysis of the fatty acids in lipid A from type B LPS revealed the presence of $3-\mathrm{OH} 10: 0,12: 0,2-\mathrm{OH} 12: 0$ and 3 -OH 12:0, in molar ratio $1 \cdot 30: 0 \cdot 51: 1 \cdot 00: 1 \cdot 74$. The same four components were found in type A LPS (Zamze et al., 1985), though in differing ratios.

After mild acid hydrolysis, each LPS yielded three carbohydrate peaks from gel filtration on Sephadex G-75 or G-50. In each case a polysaccharide was eluted at the void volume of the column, followed sequentially by two peaks (both of which also contained phosphate) representing core oligosaccharide and liberated KDO respectively, as described by Smith et al. (1985a) for the hydrolysis products of LPS from strain C28.

Complete hydrolysis of the components of the voidvolume peaks yielded glucose and thamnose, which were demonstrated by paper chromatography in all samples except those derived from cells grown with vigorous aeration, which contained only glucose. Analysis of the sugars by GC after conversion to alditol acetates confirmed that only a small quantity of rhamnose was present in the LPS of cells grown at high $\mathrm{pO}_{2}$. The molar ratio of glucose: rhamnose, determined as alditol acetates, increased with an increase in terminal $\mathrm{pO}_{2}$ in the culture (Table 1).

The changes in rhamnose and glucose content were localized in the polysaccharide fraction. Analysis by GC of the acetylated oct-2-yl rhamnosides derived from type A LPS demonstrated that the sugar was in the Dconfiguration. Identical amounts of glucose were detected in hydrolysed polysaccharide from type B LPS using glucose oxidase and phenol/sulphuric acid reagent, indicating that this sugar was also of the $\mathrm{D}$-form.

Although the gluco-polysaccharide from type B LPS eluted from Sephadex G-75 in the position expected of liberated side-chain material, the behaviour of intact type B LPS on PAGE described above indicated that this LPS was rough. The polysaccharide was apparently unattached to the LPS, and was not a species of side-chain.

\section{LPS from strain D17-A1R}

The LPS produced by strain D17-A1R contained glucose regardless of the $\mathrm{pO}_{2}$ sustained during growth. The ratio of KDO to glucose $(1: 16)$ was identical with the value found by Zamze et al. (1985). In silver-stained SDSpolyacrylamide gel electrophoretograms of the intact LPS (Fig. 2), the fast-moving band of rough LPS was accompanied by a short ladder of relatively fast-running bands in a pattern characteristic of molecular species with 
Table 2. PMAAs derived from the side-chains of LPSs from strains D10 and D17-A1R

PMAAs were separated by GC on $3 \%$ ECNSS-M at $180^{\circ} \mathrm{C}$, as described in Methods. Retention times, $t_{\mathrm{R}}$, are quoted relative to the PMAAs derived from glycogen. Molar ratios were derived from peak areas after allowing for differences in response factors by applying the correction factors of Sweet et al. (1975). GC-MS was performed as described in Methods, using a $200 \times 0.2 \mathrm{~cm}$ silanized glass column of $3 \%$ SE30 for chromatographic separation of components.

\begin{tabular}{|c|c|c|c|c|c|c|c|c|c|}
\hline \multirow[t]{3}{*}{ Identity of peak } & \multicolumn{2}{|c|}{ Published Glycogen } & \multicolumn{4}{|c|}{ D10 polysaccharide } & \multirow{2}{*}{\multicolumn{2}{|c|}{$\begin{array}{c}\text { D17-A1R } \\
\text { polysaccharide }\end{array}$}} & \multirow{3}{*}{$\begin{array}{c}\text { Mass spectrometry } \\
\text { primary ions } \\
(m / z)\end{array}$} \\
\hline & & ${ }^{2} \mathbf{R}$ & \multicolumn{2}{|c|}{ From type AB LPS } & \multicolumn{2}{|c|}{ From type B LPS } & & & \\
\hline & & & $t_{\mathrm{R}}$ & $\begin{array}{l}\text { Molar } \\
\text { ratio }\end{array}$ & $t_{\mathrm{R}}$ & $\begin{array}{l}\text { Molar } \\
\text { ratio }\end{array}$ & $t_{\mathrm{R}}$ & $\begin{array}{c}\text { Molar } \\
\text { ratio }\end{array}$ & \\
\hline $3,4-\mathrm{Me}_{2} \mathrm{Rha}$ & 0.92 & - & 0.92 & $2 \cdot 89$ & - & - & & - & 131,189 \\
\hline $2,3,4,6-\mathrm{Me}_{4} \mathrm{Glc}$ & $1 \cdot 00$ & $1 \cdot 00\}$ & $1.01+$ & $6 \cdot 18$ & $1 \cdot 00$ & $0 \cdot 80$ & $1 \cdot 00$ & $0 \cdot 83$ & $45,117,161,205$ \\
\hline $2,4-\mathrm{Me}_{2} \mathrm{Rha}$ & $1 \cdot 01$ & $-\}$ & $1.01 \dagger$ & 0.18 & - & - & - & - & $117,131,233$ \\
\hline $2,3,6-\mathrm{Me}_{3} \mathrm{Glc}$ & $2 \cdot 50$ & $2 \cdot 46$ & $2 \cdot 35$ & $4 \cdot 10$ & $2 \cdot 46$ & $4 \cdot 28$ & $2 \cdot 42$ & $4 \cdot 79$ & $45,117,233$ \\
\hline $2,3-\mathrm{Me}_{2} \mathrm{Glc}$ & $5 \cdot 39$ & $4 \cdot 95$ & 4.95 & $1 \cdot 00$ & $4 \cdot 96$ & $1 \cdot 00$ & $4 \cdot 95$ & $1 \cdot 00$ & 117,261 \\
\hline
\end{tabular}

* Published retention times for authentic standards are quoted from Jansson et al. (1976) and Smith et al. (1985b).

t These two peaks were unresolved on ECNSS-M.

truncated side-chains. A trace of silver-stained material was detected at the load origin.

Samples $(6-10 \mathrm{mg})$ of the polysaccharide recovered by gel permeation chromatography after mild acid hydrolysis of LPS from this strain revealed glucose and rhamnose present in the ratio 20:1 (as their alditol acetates).

\section{Methylation analysis of polysaccharides from LPSs of D10 and D17-A1R}

PMAAs derived from samples of the methylated polysaccharides $(6-10 \mathrm{mg})$ from type B LPS of strain D10 and LPS from D17-A1R were identified by comparing their retention times $\left(t_{\mathbf{R}}\right)$ on ECNSS-M with published values, and their mass spectra with those of authentic standards derived from permethylated glycogen. The major PMAAs detected in both samples (Table 2) were 2,3,4,6-tetra-Omethylglucitol 1,5-diacetate (2,3,4,6- $\left.\mathrm{Me}_{4} \mathrm{Glc}\right), 2,3,6$-tri-Omethylglucitol 1,4,5-triacetate $\left(2,3,6-\mathrm{Me}_{3} \mathrm{Glc}\right)$ and 2,3-di$\mathrm{O}$-methylglucitol $1,4,5,6$-tetraacetate $\left(2,3-\mathrm{Me}_{2} \mathrm{Glc}\right)$. For the polysaccharide from D10, the approximate molar ratios of the products were respectively $1: 4: 1$, which (allowing for some undermethylation of the non-reducing terminal residues) indicated a side-chain composed of $16.6 \%$ Glc $(1 \rightarrow$ (terminal $)$ groups, $66.8 \% 4) \mathrm{Glc}(1 \rightarrow$, and $16.6 \%$ of 4,6$) \mathrm{Glc}(1 \rightarrow$ (branch) residues. For D17-A1R, the ratio was approximately $1: 4 \cdot 5: 1$.

\section{NMR spectroscopy of the polysaccharide from type B LPS of strain D10}

The ${ }^{1} \mathrm{H}$-NMR spectrum for the anomeric region of polysaccharide $(20 \mathrm{mg}$ ) from type B LPS of strain D10 (Fig. 3) revealed an intense doublet prominent at $5.38-5.39$ p.p.m. $(J=3.5 \mathrm{~Hz}$; assigned to $\mathrm{H}-1$ of 4$)-\alpha-$

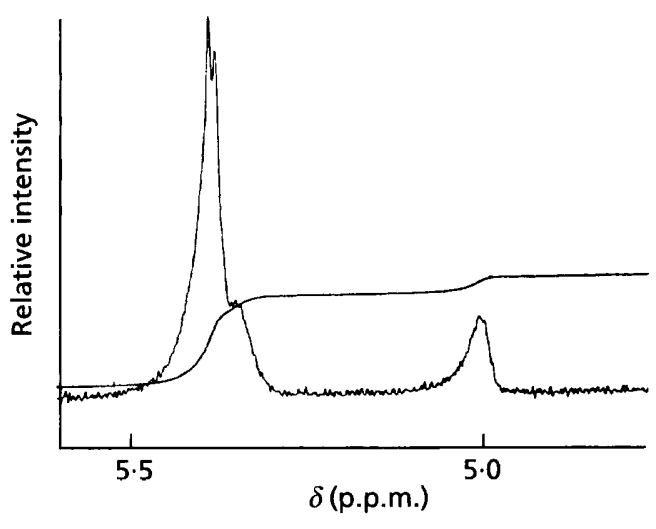

Fig. 3. ${ }^{1} \mathrm{H}-\mathrm{NMR}$ spectrum, with integration, of the anomeric region of polysaccharide from type $B$ LPS of strain D10. The spectrum was recorded at $400.13 \mathrm{MHz}$ from $20 \mathrm{mg}$ type $B$ polysaccharide derived from LPS of strain D10 grown in the fermenter with vigorous aeration, in $2.5 \mathrm{ml} 100 \% \mathrm{D}_{2} \mathrm{O}$ at $358 \mathrm{~K}$. The pulse width was $4 \mu \mathrm{s}$ and the acquisition time $1.524 \mathrm{~s}$. Chemical shifts were calculated relative to internal $\mathrm{D}_{2} \mathrm{O}(\delta=$ 4.30 p.p.m.).

Glc $(1 \rightarrow)$, with a pronounced shoulder (minor peak) at 5.35 p.p.m. (H-1 of non-reducing terminal residues, $\alpha-$ $\operatorname{Glc}(1 \rightarrow)$ (van der Veen, 1962), and a further minor peak at 5.01 p.p.m. in the resonance region for $\alpha(1 \rightarrow 6)$ linkages (4.7-4.8 p.p.m.; Meyer et al., 1978), which was assigned to 4,6$)-\alpha-G \operatorname{lc}(1 \rightarrow$. Ratios of the peak areas were $4 \cdot 2: 1: 1$ respectively, consistent with the ratios of residues indicated by methylation analysis. Signals ascribable to rhamnose H-6 (approx. 1.3 p.p.m.) were almost absent from this spectum.

The ${ }^{13} \mathrm{C}$-NMR spectrum of the same polysaccharide $(20 \mathrm{mg}$ ) contained eleven peaks (Fig. 4). The assignment 


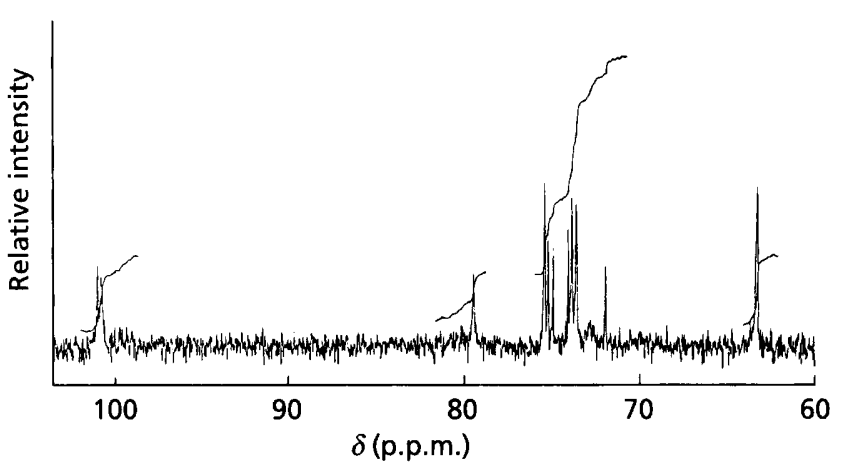

Fig. 4. ${ }^{13} \mathrm{C}-\mathrm{NMR}$ spectrum, with integration, of polysaccharide from type B LPS of strain D10. The spectrum was recorded at $100.62 \mathrm{MHz}$ from $20 \mathrm{mg}$ polysaccharide derived from type B LPS of strain D10 grown in the fermenter with vigorous aeration, in $2.5 \mathrm{ml} 100 \% \mathrm{D}_{2} \mathrm{O}$ at $358 \mathrm{~K}$. A total of 36503 accumulations were recorded, with a pulse width of $10 \mu \mathrm{s}$ and an acquisition time of $0.655 \mathrm{~s}$. Chemical shifts were calculated relative to TMS $(\delta=-2 \cdot 167$ p.p.m. $)$ in a capillary tube.

of resonances is given in Table 3. Peaks at 101.06 p.p.m. (doublet, ${ }^{1} J_{\mathrm{CH}}=181 \mathrm{~Hz}$ ) and 101.28 p.p.m. (doublet, ${ }^{1} J_{\mathrm{CH}}=181 \mathrm{~Hz}$ ) were attributed to $\alpha$-anomeric $\mathrm{C}$ atoms (Seymour et al., 1976; Usui et al., 1973; Bock \& Pederson, 1974).

The intense asymmetric signal at 62.11 p.p.m. was attributed to unsubstituted Glc C-6 (triplet; ${ }^{1} J_{\mathrm{CH}}=$ $141 \mathrm{~Hz}$ ). Three major signals (doublets, ${ }^{1} J_{\mathrm{CH}}=$ $140-152 \mathrm{~Hz}$ ) between 70 and 80 p.p.m. were assigned to C-2, C-3 and C-5 of the predominant 4$)-\alpha-G l c(1 \rightarrow$ residues (Seymouret al., 1976; Usui et al., 1973), and a signal at 78.93 p.p.m. was assigned to C-4 in linkage. Four resonances of lower intensity were assigned to the corresponding carbons of non-reducing terminal residues.

No signals were found that were uniquely attributable to the branch residue. The peak at 71.01 p.p.m., attributed above to $\mathrm{C}-4$ of $\alpha$-Glc $(1 \rightarrow 4$, may have been shared by C5 of the branch residue, which resonates at a similar value (Gorin, 1981). Resonances anticipated at $67 \cdot 3$ p.p.m. for C-6 in linkage, and at 99.5 p.p.m. for C-1 of residues linked $\alpha(1 \rightarrow 6)$ to branch residues, were not detected. Gorin (1981) reported similar difficulty in detecting these signals in spectra of $\beta$-limit dextrins from rabbit liver glycogen and plant amylopectin, and ascribed the problem to low segmental motion of the 4,6-di-O-substituted branch points.

\section{Phage A7-mediated hydrolysis of type AB LPS from strain D10}

To establish whether rhamnose and glucose were copolymerized or formed separate polysaccharides in type AB LPS, a sample $(90 \mathrm{mg}$, with a glucose : rhamnose ratio of $0.63: 1$ for the polysaccharide fraction) was incubated with phage $A 7$ for $2 \mathrm{~h}$, and the mixture was centrifuged to deposit liberated core-lipid A together with any remaining intact LPS. The low $-M_{\mathrm{r}}$ hydrolysis products recovered in the supernatant gave $\lambda_{\max }=480 \mathrm{~nm}$ when assayed with phenol/sulphuric acid reagent, consistent with a predominance of rhamnose, and amounted to approximately $6 \mathrm{mg}$ of rhamnose equivalents.

This material was separated by chromatography on a column of Sephadex G-25 to yield two peaks eluting in

Table 3. ${ }^{13} \mathrm{C}-\mathrm{NMR}$ spectroscopy: chemical shifts assigned to glucose residues in the polysaccharide from type B LPS of strain D10

\begin{tabular}{|c|c|c|c|c|c|c|c|}
\hline \multirow[t]{2}{*}{ Source } & \multirow[t]{2}{*}{ Residue } & \multicolumn{6}{|c|}{ Chemical shift (p.p.m.) } \\
\hline & & C-1 & $\mathrm{C}-2$ & C-3 & C-4 & C-5 & C-6 \\
\hline Polysaccharide from type B LPS & $\begin{array}{l}4)-\alpha-\operatorname{Glc}(1 \rightarrow \\
\alpha-G \operatorname{lc}(1 \rightarrow 4) \\
4,6)-\alpha-\operatorname{Glc}(1 \rightarrow\end{array}$ & $\begin{array}{c}101 \cdot 06 \\
101 \cdot 28 \\
\text { ND }\end{array}$ & $\begin{array}{c}73 \cdot 03 \\
74 \cdot 14 \\
?\end{array}$ & $\begin{array}{c}74 \cdot 67 \\
74 \cdot 45 \\
?\end{array}$ & $\begin{array}{c}78.93 \\
71.01 \\
?\end{array}$ & $\begin{array}{l}72 \cdot 77 \\
73 \cdot 26 \\
71 \cdot 01 ?\end{array}$ & $\begin{array}{c}62 \cdot 11 \\
62 \cdot 11 \\
\text { ND }\end{array}$ \\
\hline Maltotriose* & $\begin{array}{l}4)-\alpha-\operatorname{Glc}(1 \rightarrow \\
\alpha-\operatorname{Glc}(1 \rightarrow 4)\end{array}$ & $\begin{array}{l}101 \cdot 1 \\
101 \cdot 1\end{array}$ & $\begin{array}{l}73 \cdot 1 \\
74 \cdot 3\end{array}$ & $\begin{array}{l}74 \cdot 7 \\
75 \cdot 1\end{array}$ & $\begin{array}{l}78 \cdot 5 \\
71 \cdot 2\end{array}$ & $\begin{array}{l}72 \cdot 7 \\
73 \cdot 4\end{array}$ & $\begin{array}{l}62 \cdot 4 \\
62 \cdot 4\end{array}$ \\
\hline Pullulan $\dagger$ & 4)- $-\mathrm{-GI}(1 \rightarrow$ & $\left\{\begin{array}{l}100 \cdot 76 \\
101 \cdot 24\end{array}\right.$ & $\begin{array}{c}? \\
72 \cdot 51\end{array}$ & $\begin{array}{c}? \\
74 \cdot 38\end{array}$ & $\begin{array}{l}78 \cdot 45 \\
78 \cdot 80\end{array}$ & $\begin{array}{c}? \\
71 \cdot 30\end{array}$ & $\begin{array}{l}61 \cdot 45 \\
61 \cdot 65\end{array}$ \\
\hline D-glucan $\ddagger$ & $4)-\alpha-\operatorname{Glc}(1 \rightarrow$ & $101 \cdot 03$ & $72 \cdot 42$ & $74 \cdot 33$ & $79 \cdot 54$ & $71 \cdot 26$ & $61 \cdot 55$ \\
\hline Panose $\$$ & $\alpha-G \operatorname{lc}(1 \rightarrow 6)$ & $99 \cdot 3$ & $73 \cdot 1$ & $74 \cdot 6$ & $71 \cdot 2$ & $73 \cdot 1$ & $62 \cdot 4$ \\
\hline$\beta$-Limit dextrin $\|$ & $4,6)-\alpha-\operatorname{Glc}(1 \rightarrow$ & ? & $?$ & $?$ & $?$ & $71 \cdot 0$ & $67 \cdot 3$ \\
\hline
\end{tabular}

ND, No plausible signal detected.

* Maltotriose, $\alpha$-Glc $p(1 \rightarrow 4)-\alpha$-Glc $p(1 \rightarrow 4)$-Glc (Usui et al., 1973).

† Pullulan Y6992, containing $\alpha$-Glc $p(1 \rightarrow 4)$ - and $\alpha$-Glc $p(1 \rightarrow 6)$-linked residues (Seymour et al., 1976).

$\ddagger$ Glucan B1254, containing $\alpha$-Glc $p(1 \rightarrow, \alpha$-Glc $p(1 \rightarrow 4), \alpha$-Glc $p(1 \rightarrow 6)$ and $\alpha$-Glc $p(1 \rightarrow 4,6)$-linked residues (Seymour $e t$ al., 1976$)$.

$\S$ Panose, $\alpha$-Glc $p(1 \rightarrow 6)-\alpha$-Glc $p(1 \rightarrow 4)$-Glc (Usui et al., 1973).

$\| \beta$-Limit dextrin from rabbit liver glycogen (see Gorin, 1981). 
Table 4. ${ }^{13} \mathrm{C}$-NMR spectroscopic chemical shifts of polysaccharide from type AB LPS of strain D10

\begin{tabular}{|c|c|}
\hline $\begin{array}{l}\text { Chemical shift } \\
\text { (p.p.m.)* }\end{array}$ & Possible identity \\
\hline $16.95(\mathrm{~L})$ & C- 6 of 3$)-\alpha-\operatorname{Rha}(1 \rightarrow$ \\
\hline $17 \cdot 05(\mathrm{M})$ & C- 6 of 2$)-\alpha-\operatorname{Rha}(1 \rightarrow$ \\
\hline $61 \cdot 10((\mathrm{~S} \dagger)$ & C-6 of 4$)-\alpha-\operatorname{Glc}(1 \rightarrow$ and $\alpha-\operatorname{Glc}(1 \rightarrow$ \\
\hline $69 \cdot 55(\mathrm{~L})$ & $\mathrm{C}-5$ of 3$)-\alpha-\mathrm{Rha}(1 \rightarrow$ \\
\hline $69 \cdot 75(\mathrm{M})$ & C- 5 of 2$)-\alpha-$ Rha( $1 \rightarrow$ \\
\hline $70 \cdot 30(\mathrm{~L})$ & C-3 of 2$)-\alpha-\operatorname{Rha}(1 \rightarrow$ \\
\hline $70 \cdot 40(\mathrm{~L})$ & $\mathrm{C}-2$ of 3$)-\alpha-\mathrm{Rha}(1 \rightarrow$ \\
\hline $70 \cdot 55(\mathrm{~L})$ & $\begin{array}{l}C-4 \text { of } \alpha-G \operatorname{lc}(1 \rightarrow \text { and } C-5 \text { of } \\
4,6)-\alpha-G \operatorname{lc}(1 \rightarrow ?\end{array}$ \\
\hline $71 \cdot 80(\mathrm{~L})$ & C-4 of 3$)-\alpha-\operatorname{Rha}(1 \rightarrow$ \\
\hline $72 \cdot 00(\mathrm{~L})$ & C-4 of 3$)-\alpha-$ Rha( $1 \rightarrow$ \\
\hline $72 \cdot 75(\mathrm{M})$ & $\begin{array}{l}\text { C-5 of } 4)-\alpha-G l c(1 \rightarrow \text { and } C-4 \text { of } \\
2)-\alpha-\operatorname{Rha}(1 \rightarrow\end{array}$ \\
\hline $73 \cdot 40(S)$ & $\begin{array}{l}\mathrm{C}-2 \text { of } 4)-\alpha-G \mathrm{lc}(1 \rightarrow \text { and } / \text { or } C-5 \text { of } \\
\alpha-G \operatorname{lc}(1 \rightarrow ?\end{array}$ \\
\hline $73.65(S)$ & $?$ \\
\hline $78 \cdot 20(\mathrm{M})$ & C-3 of 3$)-\alpha-$ Rha $(1 \rightarrow$ \\
\hline $78 \cdot 35(\mathrm{M})$ & $C-2$ of 2$)-\alpha-\operatorname{Rha}(1 \rightarrow$ \\
\hline $101 \cdot 10(\mathrm{M})$ & C-1 of 2$)-\alpha-$ Rha $) 1 \rightarrow$ or 4$)-\alpha-\operatorname{Glc}(1 \rightarrow$ \\
\hline $102 \cdot 20(\mathrm{~L})$ & C-1 of 3$)-\alpha-\operatorname{Rha}(1 \rightarrow$ or $\alpha-\operatorname{Glc}(1 \rightarrow$ \\
\hline
\end{tabular}

* $(\mathrm{L}),(\mathrm{M}),(\mathrm{S})$ refer to large, medium and small peaks (based on visual estimates of intensities). In this polysaccharide, rhamnose:glucose was $1: 0.63$; therefore glucose signals were expected to be the weaker.

† Broad grouping of weak signals.

the positions of a hexa- and a trisaccharide respectively. The monosaccharides liberated by hydrolysis of the presumed hexasaccharide were converted to the corresponding alditol acetates and analysed by GC to reveal rhamnitol pentaacetate and glucitol hexaacetate in molar ratio 16:1. The presumed trisaccharide was not examined, although the reaction product with phenol/sulphuric acid also gave $\lambda_{\max }=480 \mathrm{~nm}$.

Methylation analysis of the presumed hexasaccharide confirmed its identity with the rhamnose hexasaccharide recovered from the digestion of side-chains from LPS of strain C28 by phage A7 (Smith et al., 1994). The presumed trisaccharide was not examined.

The pellet recovered by ultracentrifugation of the LPS after digestion with phage A7 contained a total of $3.1 \mathrm{mg}$ of glucose and $1.2 \mathrm{mg}$ of thamnose (glucose : rhamnose $\approx$ $2 \cdot 6: 1)$.

On a column of Sepharose 4B, the products formed by the action of phage A7 on $5 \mathrm{mg}$ of type B LPS yielded a large carbohydrate peak eluting at the void volume. Only a small quantity of rhamnose oligosaccharide emerged at the totally-included volume. The elution profile was almost identical with that produced by Zamze (1983) after treatment of LPS from strain D17-A1R with phage A7.

Taken together, the data indicate that rhamnose and glucose in type AB LPS did not form a co-polymer.

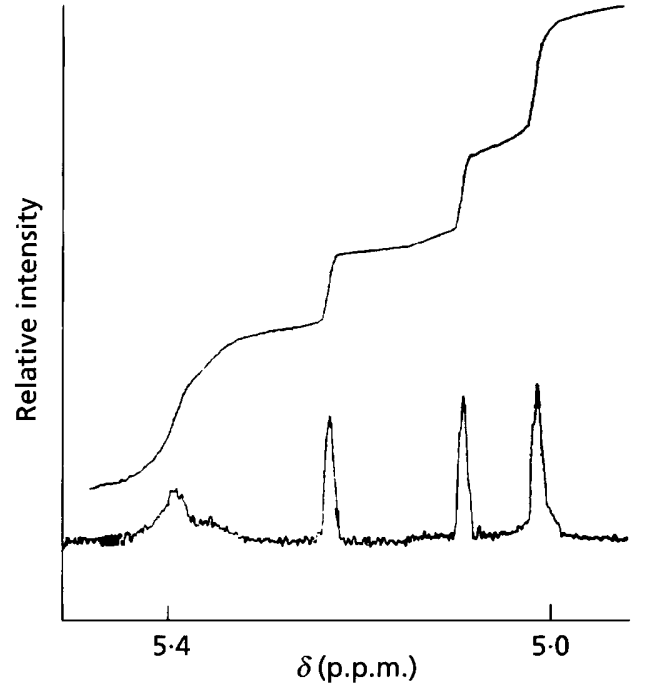

Fig. 5. ${ }^{1} \mathrm{H}-\mathrm{NMR}$ spectrum, with integration, of the anomeric region of polysaccharide from type AB LPS of strain $D 10$. The spectrum was recorded at $400.13 \mathrm{MHz}$ from $20 \mathrm{mg}$ polysaccharide derived from type AB LPS of strain D10 grown in the fermenter with moderate aeration, in $2.5 \mathrm{ml} 100 \% \mathrm{D}_{2} \mathrm{O}$ at $358 \mathrm{~K}$. The pulse width was $4 \mu \mathrm{s}$ and the acquisition time $3.998 \mathrm{~s}$. Chemical shifts were calculated relative to internal $\mathrm{D}_{2} \mathrm{O}(\delta=$ 4.30 p.p.m.).

\section{Methylation analysis of type AB LPS from strain D10}

PMAAs derived from the methylated polysaccharide derived from type AB LPS of strain D10, when analysed by GC on a column of ECNSS-M, yielded four major peaks (Table 2), the first of which was 3,4-di-Omethylrhamnitol 1,2,5-triacetate $\quad\left(3,4-\mathrm{Me}_{2} \mathrm{Rha} ; t_{\mathrm{R}}=\right.$ $0.92)$. The second $\left(t_{\mathrm{R}}=1 \cdot 01\right)$ contained $2,3,4,6-\mathrm{Me}_{4} \mathrm{Glc}$ and 2,4-di-O-methylthamnitol 1,3,5-triacetate (2,4$\mathrm{Me}_{2} \mathrm{Rha}$ ) as minor and major unresolved components respectively. The third and fourth peaks were 2,3,6$\mathrm{Me}_{3} \mathrm{Glc}\left(t_{\mathrm{R}}=2 \cdot 35\right)$ and 2,3-Me $\mathrm{Mlc}_{2}\left(t_{\mathrm{R}}=4 \cdot 95\right)$. All components, including the two unresolved PMAAs of the second peak, were subsequently separated on $3 \%$ SE30 and identified by mass spectrometry.

The demonstration of 2,4- and 3,4- $\mathrm{Me}_{2} \mathrm{Rha}$ as the major PMAAs in this sample indicated that the rhamnan in type $\mathrm{AB}$ polysaccharide was structurally identical with the side-chain of strain C28 (Smith et al., 1985b).

\section{NMR spectroscopy of polysaccharide from type $A B$ LPS of strain D10}

The anomeric region of the ${ }^{1} \mathrm{H}$-NMR spectrum of type $\mathrm{AB}$ polysaccharide $(20 \mathrm{mg})$ from strain D10 (Fig. 5) displayed three singlet signals at 5.23, 5.08 and $5 \cdot 01$ p.p.m., which were of approximately equal intensity and similar to those found in the spectrum of the rhamnan from strain C28 (Smith et al., 1985b). Also present were the resonances assigned above to anomeric protons of $\alpha$ glucopyranose residues: a broad peak at 5.39 p.p.m. with a shoulder at 5.36 p.p.m., and a shoulder at 5.00 p.p.m. to 
the signal at $5 \cdot 01$ p.p.m. The ratio of the combined peak areas of signals attributed to rhamnose and to glucose accorded with the glucose: rhamnose ratio $(1: 1.59)$ for the polysaccharide mixture. The two doublets centred on $1 \cdot 3$ p.p.m. associated with rhamnose $\mathrm{H}-6$ amounted to three protons per rhamnose $\mathrm{H}-1$. The spectrum was therefore derived additively from the spectra of the two individual polymers.

A ${ }^{13} \mathrm{C}-\mathrm{NMR}$ spectrum obtained from the same sample was of poor quality, but likewise appeared to be derived from the spectra of two separate polymers. Major peaks detected are identified in Table 4.

\section{DISCUSSION}

Extraction of cells of the plum isolate $P$. syringae pv. morsprunorum strain D10 and the phage-resistant mutant D17-A1R with aqueous phenol yielded LPS preparations containing glucans which resembled glycogen in residue composition. The ${ }^{13} \mathrm{C}-\mathrm{NMR}$ spectrum of the glucan from strain D10 was also glycogen-like, but neither the precise structure of this material, nor its original cellular location, has been determined.

Unlike D17-A1R, strain D10 also synthesized a Drhamnan identical with the side-chain produced by the cherry isolate C28. The loss of the rhamnan and appearance of the glucan occurred when the $\mathrm{pO}_{2}$ during culture was increased. At intermediate $\mathrm{pO}_{2}$ values, both polymers were present; from batch to batch of LPS a continuous variation was observed in the ratio of the two sugars. Evidence for covalent attachment of the glucan to lipid A was sought by examining the chromatographic behaviour of the alkaline de-O-acylation products of LPS. As evidence of structural association, the co-elution of these two components during chromatography was almost certainly misleading; SDS-PAGE of intact type B LPS did not give the ladder pattern characteristic of smooth LPS. It is possible that the glucan did not react with silver strain, but that is unlikely since the predominant residue in the polymer is $(1 \rightarrow 4)$-linked glucose, which should be susceptible to periodate oxidation and should therefore have reacted with silver once oxidized. Glucan not attached to the LPS would have remained at the origin during electrophoresis; traces of stained material were in fact detected around this position on the electrophoretogram of type B LPS. The available evidence therefore indicates that type B LPS was rough. Since rough LPS is not normally easily extracted from cells with aqueous phenol, the physical association between glucan and LPS, established before or during extraction, may have enhanced the solubility of the LPS in this reagent.

Nor was there any evidence in type AB LPS that strain D10 produced a heteropolysaccharide containing both sugars. Both methylation analysis and NMR spectroscopy indicated the simultaneous presence of two distinct polymers. Further evidence was provided by demonstrating that rhamnose was selectively liberated by the action of phage A7 rhamnanase, yielding oligosaccharides similar to those derived from the side-chain of strain C28 by the same treatment (Smith et al., 1994).
The effect of $\mathrm{pO}_{2}$ on LPS structure requires further investigation. Since $P$. syringae is an obligate aerobe, the effect may simply be to limit the growth rate, which more directly determines LPS type. This possibility could be examined by comparing the LPSs recovered from organisms grown with constant $\mathrm{pO}_{2}$ at different dilution rates in a chemostat. Alternatively, the controlling factor could be $\mathrm{PCO}_{2}$, since the rate at which carbon dioxide is swept from liquid culture is dependent on agitation and aeration intensity (Lilly, 1983). Chester \& Meadow (1975) found that LPS of $P$. aeruginosa varied in composition depending on the growth vessel employed, but did not investigate the influence of partial pressure of dissolved gases.

Although the core regions of types AB and B LPS have not yet been rigorously examined, Zamze et al. (1985) demonstrated that the cores of LPSs from cherry and plum isolates of $P$. syringae pv. morsprunorum were similar in composition. In the present investigation the same four fatty acids were found in the lipid A of type B as in type A LPS.

The ability to produce two distinct species of LPS may have ecological or pathological significance, since there is evidence that the composition of the cell surface in plantpathogenic pseudomonads affects virulence. Mutants of cherry isolates of pv. morsprunorum resistant to LPSbinding phages such as A7 have rough LPS (Zamze $e$ t al., 1985) and display diminished virulence (Garrett et al., 1974). The role of LPS in plant disease is by no means clear; for example, Hignett et al. (1986) found that pretreatment of cherry leaf scars with the side-chain from LPS of strain C28 inhibited the development of canker after subsequent inoculation with cells of strain C28.

Both cherry and plum isolates of $P$. syringae pv. morsprunorum are epiphytic during the summer, entering the plant in the autumn to overwinter (Crosse \& Garrett, 1970). In cherry isolates such as $\mathrm{C} 28, \mathrm{pO}_{2}$ does not affect the type of LPS formed in culture, but in view of the observed influence of environmental factors on LPS structure in strain D10, it is conceivable that plum isolates could elaborate rough LPS when growing epiphytically under conditions of high $\mathrm{pO}_{2}$, and smooth LPS during growth within the host. Cherry strains enter the plant primarily through the leaf scars; plum isolates are predominantly wound pathogens. It is possible that plum strains do not establish infections via leaf scars because the rough LPS that they present on entry triggers plant defence mechanisms. Conversely, moribund tissue at wound sites might offer no resistance to saprophytic growth of the organism, which would cause a local fall in $\mathrm{pO}_{2}$, allowing in turn the synthesis of the side-chain, and enabling the organism to penetrate into neighbouring healthy tissue. By contrast, when plum isolates grow as epiphytes, they are exposed to attack by LPS-binding phages. In such conditions, presentation of rough LPS (and glucan?) at the cell surface might assist in ensuring their survival.

The production of glucan by strain D17-A1R was unaffected by $\mathrm{pO}_{2}$ in culture. As a mutant resistant to an 
LPS-binding phage, this organism should be rough. In the parent strain (D17), Zamze et al. (1985) found that the rhamnose-bearing polysaccharide fraction recovered after mild acid hydrolysis of the LPS also contained $27 \%$ glucose. Strain D17 may therefore be capable of producing substantial quantities of glucan. Since this biosynthetic capability should not have been affected by mutation to phage resistance, a mutant such as D17-A1R might plausibly synthesize the polymer regardless of growth conditions.

\section{ACKNOWLEDGEMENTS}

We thank Dr C. M. E. Garrett, Horticultural Research International, East Malling, Kent, UK, for cultures; Hazel Aucken of the Laboratory of Hospital Infection, Central Public Health Laboratory, Colindale, London, UK, for analysis of intact LPSs by PAGE, and the SERC High Field NMR Service, Warwick University, LK, for NMR spectra.

\section{REFERENCES}

Aucken, H. N. \& Pitt, T. L. (1993). Lipopolysaccharide profile typing as a technique for comparative typing of Gram-negative bacteria. J Clin Microbiol 31, 1286-1289.

Bock, K. \& Pederson, C. (1974). Carbon-13-hydrogen coupling constants in hexopyranoses. J Chem Soc Perkin Trans 2, 293-297.

Borkowski, J. D. \& Johnson, M. J. (1967). Long-lived steam sterilizable membrane probes for dissolved oxygen measurement. Biotecbnol Bioeng 9, 635-639.

Chester, I. R. \& Meadow, P. M. (1975). Heterogeneity of the lipopolysaccharide from Pseudomonas aeruginosa. Eur J Biochem 58, 273-282.

Crosse, J. E. \& Garrett, C. M. E. (1963). Studies on the bacteriophagy of Pseudomonas morsprunorum, Ps. syringae and related organisms. J Appl Bacteriol 26, 159-177.

Crosse, J. E. \& Garrett, C. M. E. (1970). Pathogenicity of Pseudomonas morsprunorum in relation to host specificity. $J$ Gen Microbiol 62, 315-327.

Dubois, M., Gilles, K. A., Hamilton, J. K., Rebers, P. A. \& Smith, F. (1956). Colorimetric method for determination of sugars and related substances. Anal Chem 28, 350-356.

Garrett, C. M. E., Panagopoulos, C. G. \& Crosse, J. E. (1966). Comparison of plant pathogenic pseudomonads from fruit trees. $J$ Appl Bacterio/ 29, 342-356.

Garrett, C. M. E., Crosse, J. E. \& Sletten, A. (1974). Relations between phage sensitivity and virulence in Pseudomonas morsprunorum. J Gen Microbiol 80, 475-483.

Gorin, P. A. J. (1981). Carbon-13 nuclear magnetic resonance spectroscopy of polysaccharides. Adv Carbobydr Chem Biochem 38, 13-104.

Helander, I. M. (1985). Isolation and electrophoretic analysis of bacterial lipopolysaccharides. In Enterobacterial Surface Antigens: Methods for Molecular Characterization, pp. 262-274. Edited by T. K. Korhonen, E. A. Dawes \& P. H. Mäkelä. Amsterdam: Elsevier.

Hignett, R. C., Zamze, S. E., Munro, S. M. \& Smith, A. R. W. (1986). Inhibition by bacterial lipopolysaccharide of wilt induced by phytopathogenic bacteria in cut cherry shoots, and of cherry canker disease. Plant Pathol 35, 270-276.
Jansson, P. E., Kenne, L., Liedgren, H., Lindberg, B. \& Lönngren, J. (1976). A Practical Guide to the Methylation Analysis of Carbobydrates. Chem Commun 8. Stockholm: Stockholm University. Klement, Z. (1963). Rapid detection of the pathogenicity of phytopathogenic pseudomonads. Nature 199, 299-300.

Lilly, M. D. (1983). Problems in process scaleup. In Bioactive Microbial Products 2: Development and Production (Special Publication of the Society for General Microbiology no. 10), pp. 79-89. Edited by L. J. Nisbet \& D. J. Winstanley. London: Academic Press.

Meyer, T. S., Lamberts, B. L. \& Egan, R. S. (1978). Structural studies of extracellular glucans of Streptococcus mutans by proton magnetic resonance. Carbobydr Res 66, 33-42.

Munro, S. M., Smith, A. R. W., Hignett, R. C. \& Wait, R. (1986). Lipopolysaccharide of Pseudomonas morsprunorum (abstract). Fourteenth International Congress of Microbiology, p. 285. IUMS/Royal Society, Manchester, 7-13 September.

Osborn, M. J. (1963). Studies on the Gram-negative cell wall. I. Evidence for the role of 2-keto-3-deoxyoctonate in the lipopolysaccharide of Salmonella typhimurium. Proc Natl Acad $S_{c i}$ USA 50, 499-506.

Ray, T. C., Smith, A. R. W., Wait, R. \& Hignett, R. C. (1987). Structure of the side-chain of lipopolysaccharide from Erwinia amylovora strain T. Eur J Biocbem 170, 357-361.

Seymour, F. R., Knapp, R. D. \& Bishop, S. H. (1976). Determination of the structure of dextran by ${ }^{13} \mathrm{C}$-nuclear magnetic resonance spectroscopy. Carbobydr Res 51, 179-194.

Smith, A. R. W., Zamze, S. E. \& Hignett, R. C. (1985a). Composition of lipopolysaccharide from Pseudomonas syringae pv. morsprunorum and its digestion by bacteriophage A7. J Gen Microbiol 131, 963-974.

Smith, A. R. W., Zamze, S. E., Munro, S. M., Carter, K. J. \& Hignett, R. C. (1985b). Structure of the side-chain of lipopolysaccharide from Pseudomonas syringae pv. morsprunorum C28. Eur J Biochem 149, 73-78.

Smith, A. R. W., Zamze, S. E. \& Hignett, R. C. (1994). Morphology and hydrolytic activity of $\mathrm{A} 7$, a typing phage of $P$ seudomonas syringae pv. morsprunorum. Microbiology 140, 905-913.

Sweet, D. P., Shapiro, R. H. \& Albersheim, P. (1975). Quantitative analysis by various GLC response-factor theories for partially methylated and partially ethylated alditol acetates. Carbohydr Res 40, 217-225.

Usui, T., Yamaoka, N., Matsuda, K., Tuzimura, K., Sugiyama, H. \& Seto, S. (1973). ${ }^{13} \mathrm{C}-\mathrm{Nuclear}$ magnetic resonance spectra of glucobioses, glucotrioses and glucans. J Chem Soc Perkin Trans 1, 2425-2432.

van der Veen, J. M. (1962). An NMR study of the glycoside link in glycosides of glucose and galactose. J Org Chem 28, 564-566.

Zamze, S. E. (1983). The structure of lipopolysaccharide from Pseudomonas syringae pv. morsprunorum and its role in cherry canker. $\mathrm{PhD}$ thesis, Council for National Academic Awards; Thames Polytechnic.

Zamze, S. E., Smith, A. R. W. \& Hignett, R. C. (1985). Composition of lipopolysaccharide from strains of Pseudomonas syringae $\mathrm{pv}$. morsprunorum of differing host specificity and virulence. $J$ Gen Microbiol 131, 1941-1950.

Zamze, S. E., Smith, A. R. W. \& Hignett, R. C. (1986). Composition of lipopolysaccharides from Pseudomonas syringae pv. syringae and a serological comparison with lipopolysaccharide from $P$. syringae $\mathrm{pv}$. morsprunorum. J Gen Microbiol 132, 3393-3401.

Received 10 August 1993; revised 24 January 1994; accepted 31 January 1994. 